\title{
The Relationship Between Maternal Vitamin E and Progress of Children Asthma: A Review Article
}

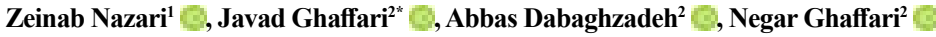 \\ 1. Department of Gynecology, Faculty of Medicine, Mazandaran University of Medical Sciences, Sari, Iran \\ 2. Pediatric Infectious Diseases Research Center, Mazandaran University of Medical Sciences, Sari, Iran.
}

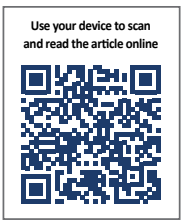

ctitation Nazari Z, Ghaffari J, Dabaghzadeh A, Ghaffari N. The Relationship Between Maternal Vitamin E and Progress of Children Asthma: A Review Article. Research in Molecular Medicine. 2020; 8(2):51-54. https://doi.org/10.32598/rmm.8.2.188.1

https://doi.org/10.32598/rmm.8.2.188.1

sthma is one of the most common chronic inflammatory respiratory disorA ders with many different presentations. It has different endotypes and genotypes and causes significant morbidity and mortality in both children and adults. Asthma is the most common cause of emergency department visits, absence from school, and hospitalization in children. Common clinical manifestations of childhood asthma are cough, wheezing, and dyspnea. More than 300 million people are affected in the world. The prevalence of asthma is varied in different regions of the world. Asthma's prevalence rates are $2.7 \%$ and $3.5 \%$ in children aged 6-7 and 13-14 years, respectively $[1,2]$. The disorder is more common in children than adults [1-3].

The prevalence of asthma has increased in the past few decades, probably due to environmental and or genetic susceptibilities, economic, and nutritional factors [4, 5]. Asthma has a high financial and emotional burden on the family and the country's health services [6]. Although the etiology of asthma is not exactly clear, we know that genetic and environmental factors play important roles in inducing and exacerbating asthma. Different cytokines and chemokines such as interleukin (IL)-6 and IL-8 contribute to the pathogenesis of asthma [7-9]. The diagnosis of asthma is mainly based on the patient's history and physical examination. Treatments of asthma include risk factors avoidance (indoor and outdoor allergens), pharmacotherapy for rescue and maintenance treatments, and specific allergen immunotherapy in particular instances [1].

Vitamin E is a lipid-soluble substance that protects epithelial tissues from damages caused by antioxidants. It contains four isomers of $\alpha, \beta, \gamma, \sigma$, amongst which, $\alpha$ - tocopherol is an essential isomer. The first defensive line against oxygen free radicals is antioxidant agents. The respiratory tracts fluid contains antioxidants agents such as $\alpha$-tocopherol (vitamin E). These antioxidants are found in nutrients like fruits and vegetables $[10,11]$. This vitamin improves T-cells, granulocytes functions, the blood supply, and tissue repair and suppresses $\operatorname{IgE}$ response to allergic agents $[12,13]$. Vitamin $\mathrm{E} \alpha$ - and $\gamma$-tocopherol isoforms have different effects on allergic inflammation, such as asthma $[14,15]$. In a clinical trial study by Ghaffari et al., vitamin E supplements were shown to improve clinical manifestations and pulmonary function tests in children with asthma [16].

Vitamin $\mathrm{E}$ is an essential factor for lung development in the fetus. Maternal tobacco smoking can decrease vitamin E intake, causing fetal growth restriction and respiratory disorders such as asthma in children [17]. This study aims to review the effects of maternal vitamin $\mathrm{E}$ levels during gestation and the prevalence of asthma in their children. In a cohort study, higher levels of both

\footnotetext{
* Corresponding Author:

Javad Ghaffari, PhD.

Address: Pediatric Infectious Diseases Research Center, Mazandaran University of Medical Sciences, Sari, Iran

Phone: +98 (911) 3510359

E-mail:javadneg@yahoo.com; jghaffari94@gmail.com
} 
$\alpha$-tocopherol and $\gamma$-tocopherol isoforms concentrations in maternal post-partum plasma were found to be associated with a decreased likelihood of wheezing, requiring asthma medications at two years old [14].

Higher maternal vitamin E intake during pregnancy is associated with reduced risk of children being diagnosed with asthma and increased FeNO in 5-year-old children [18]. Lower consumption of vitamin E during pregnancy is associated with an increased risk of diagnosed asthma and wheeze in children in the first ten years of life [19]. There was no association between maternal vitamin $\mathrm{E}$ and the prevalence of childhood asthma at the ages of 18 months and 7 years [20].

Maternal vitamin E intake is associated with a reduction in childhood wheeze but not asthma [21]. In another study, the consumption of dietary sources of vitamin $\mathrm{E}$ during pregnancy was not associated with decreased respiratory outcomes in children [22]. Maternal vitamin E intake during pregnancy is associated with decreased wheezing in children's second year of life but not the first year [23]. Vitamin E is a fat-soluble antioxidant substance that improves fetal lung growth and reduces respiratory disorders such as asthma in childhood. Vitamin E also decreases oxidative stress, airway inflammation, and Th2 cells. Vitamin E level in maternal plasma is not routinely checked during pregnancy. We believe that vitamin $\mathrm{E}$ is an antioxidant that may protect children against asthma when taken during pregnancy. In this review, a few articles reported that vitamin E supplement or food enrichment during pregnancy decreased wheezing and or asthma in children. Still, a few articles revealed no significant association between maternal vitamin $\mathrm{E}$ and asthma in children.

Some studies report that lower intake of dietary vitamin E during pregnancy increases asthma and wheezing in childhood [12, 19, 23-25]. Allen et al. concluded that lower plasma $\alpha$-tocopherol in the first trimester in mothers makes it more likely that their children are treated for asthma when they are ten years old [19]. Other studies revealed that maternal vitamin $\mathrm{E}$ is not related to the children's asthma and or wheezing [20, 22, 26, 27]. Cohort studies were rare; however, West et al. followed children for seven years and found no association between vitamin $\mathrm{E}$ intake during pregnancy and childhood asthma. Children's wheezing increased in this study [26]. The same results were found in Greenough et al. cohort study in 2-year-old children [28]. Because the follow-up duration is different between the two studies (two years and seven years), the results might be affected by that.
In contrast, some studies reported that vitamin $\mathrm{E}$ intake during pregnancy decreases children's asthma and or wheezing at the age of two years and five years [23-25]. We think the best way to evaluate the correlation between maternal vitamin E with children's wheezing and or asthma is to assess maternal plasma vitamin E, especially $\alpha$-tocopherol. In most of the review articles, we did not find this correlation. Even in prospective or retrospective studies of different diets such as western and Mediterranean, the results are varied [21]. The possible reasons for different results are different study designs and populations, duration of the study, sample size, the dose of vitamin E, serum vitamin E, variable nutrition, geographic area, and other contributing factors. Noteworthy, there is no threshold level of vitamin E intake during pregnancy to protect against asthma and or wheezing.

In conclusion, Vitamin E supplement during pregnancy has different effects on wheezing or asthma prevalence in children. We need more prospective cohort and or clinical research studies along with the evaluation of maternal plasma vitamin E level.

\section{Ethical Considerations}

\section{Compliance with ethical guidelines}

All ethical principles were considered in this article.

\section{Funding}

This research did not receive any specific grant from funding agencies in the public, commercial, or not-for profit sectors.

\section{Authors contribution's}

Review, search and draft-writing: Javad Ghaffari; Review, search: Abbas Dabaghzadeh; Editing: Negar Ghaffari; Supervision: Zeinab Nazari.

\section{Conflict of interest}

The authors declared no conflict of interest.

\section{Acknowledgements}

The authors would like to thank the Clinical Research Development Unit (CRDU) of Bu-Ali Sina hospital, Mazandaran University of Medical Sciences (Sari, Iran) for their support, cooperation and assistance throughout the study period. 


\section{References}

[1] Ghaffari J, Aarabi M. The prevalence of pediatric asthma in the Islamic Republic of Iran: A systematic review and meta-analysis. J Pediatr Rev. 2013; 1:2-11.

[2] Zamanfar D, Gaffari J, Behzadnia S, Yazdani-charati J, Tavakoli $\mathrm{S}$. The prevalence of allergic rhinitis, eczema and asthma in students of guidance schools in Mazandaran Province, Iran. Open Access Maced J Med Sci. 2016; 4(4):619-23. [DOI:10.3889/oamjms.2016.112] [PMID] [PMCID]

[3] Ghaffari J. Prevalence of asthma, allergic rhinitis and eczema in elementary schools in Sari (Iran). Caspian J Intern Med. 2012; 3:372-6.

[4] Ghaffari J. The prevalence of children's asthma: A few comments Clin Respir J. 2018; 12(9):2454. [DOI:10.1111/crj.12913] [PMID]

[5] Ariaee N, Farid R, Shabestari F, Shabestari M, Jabbari Azad F. Trace elements status in sera of patients with allergic asthma. Rep Biochem Mol Biol. 2016; 5(1):20-5.

[6] Ghaffari J, Hadian A, Daneshpoor SMM, Khademloo M. Asthma burden in the hospitalized patients. Int J Pediatr. 2014; 2(10):25563.

[7] Hatami H, Ghaffari N, Ghaffari J, Rafatpanah H. Role of cytokines and chemokines in the outcome of children with severe asthma. J Pediatr. Rev. 2019; 7(1):17-28 [DOI:10.32598/jpr.7.1.17]

[8] Aghajani M, Rafiei A, Ghaffari J, Valadan R, Kardan M. Immune dysregulation in children with allergic asthma, a close relationship between IL-17 but not IL-4 or IFN-g, and disease severity. Res Mol Med (RMM). 2018; 6(1):16-29. [DOI:10.18502/rmm. v6i1.3926]

[9] Kardan M, Ghaffari J, Valadan R, Rafiei A, Soltani M, Aghajani $\mathrm{M}$ et al . T-bet and GATA-3 gene expression in children with allergic asthma and healthy controls. J Mazandaran Univ Med Sci. 2017; 26(146):9-21.

[10] Wood LG, Garg ML, Smart JM, Scott HA, Barker D, Gibson PG Manipulating antioxidant intake in asthma: A randomized controlled trial. Am J Clin Nutr. 2012; 96(3):534-43. [DOI:10.3945/ ajcn.111.032623] [PMID]

[11] Romieu I, Sienra-Monge JJ, Ramírez-Aguilar M, Téllez-Rojo MM, Moreno-Macías H, Reyes-Ruiz NI, et al. Antioxidant supplementation and lung functions among children with asthma exposed to high levels of air pollutants. Am J RespirCrit Care Med. 2002; 166(5):703-9. [DOI:10.1164/rccm.2112074] [PMID]

[12] Devereux G, Turner SW, Craig LC, McNeill G, Martindale S, Harbour PJ, et al. Low maternal vitamin E intake during pregnancy is associated with asthma in 5-year-old children. Am J Respir Crit Care Med. 2006; 174(5):499-507. [DOI:10.1164/ rccm.200512-1946OC] [PMID]

[13] Fogarty A, Lewis S, Weiss ST, Britton J. Dietary vitamin E IgE concentrations, and atopy. Lancet. 2000; 356(9241):1573-4. [DOI:10.1016/S0140-6736(00)03132-9]

[14] Stone CA, Cook-Mills JA, Gebretsadik T, Larkin EK, RosasSalazar C, Conolly A, et al. Maternal vitamin E plasma isoform concentrations and association with child wheezing and asthma outcomes. JACI. 2017; 139(2):Suppl-AB83. [DOI:10.1016/j. jaci.2016.12.222]

[15] Ghaffari J, Ashrafi H, Ranjbar AR, Nazari Z. Vitamin E in children with asthma: A review. J Pediatr Rev. 2014; 2(2):57-65.
[16] Ghaffari J, Farid Hossaini R, Khalilian A, Nahanmoghadam N, Salehifar E, Rafatpanah H. Vitamin E supplementation, lung functions and clinical manifestations in children with moderate asthma: A randomized double blind placebo- controlled trial. Iran J Allergy Asthma Immunol. 2014; 13(2):98-103.

[17] Turner SW, Campbell D, Smith N, Craig LC, McNeill G, Forbes $\mathrm{SH}$, et al. Associations between fetal size, maternal \{alpha\}tocopherol and childhood asthma. Thorax. 201; 65(5):391-7. [DOI:10.1136/thx.2008.111385] [PMID]

[18] Devereux G, Craig L, Seaton A, Turner S. Maternal vitamin D and $E$ intakes in pregnancy and asthma to age 15 years: A cohort study. Pediatric Pulmonology. 2018; 54(1):11-9. [DOI:10.1002/ ppul.24184.] [PMID]

[19] Allan KM, Prabhu N, Craig LC, McNeill G, Kirby B, McLay J, et al. Maternal vitamin $D$ and $E$ intakes during pregnancy are associated with asthma in children. Eur Respir J. 2015; 45(4):1027-36 [DOI:10.1183/09031936.00102214] [PMID]

[20] Maslova E, Hansen S, Strøm M, Halldorsson TI, Olsen SF. Maternal intake of vitamins $\mathrm{A}, \mathrm{E}$ and $\mathrm{K}$ in pregnancy and child allergic disease: A longitudinal study from the Danish National Birth Cohort. Br J Nutr. 2014; 111(6):1096-108. [DOI:10.1017/ S0007114513003395] [PMID]

[21] Beckhaus AA, Garcia-Marcos L, Forno E, Pacheco-Gonzalez RM, Celedón JC, Castro-Rodriguez JA. Maternal nutrition during pregnancy and risk of asthma, wheeze, and atopic diseases during childhood: A systematic review and meta-analysis. Allergy. 2015; 70(12):1588-604. [DOI:10.1111/all.12729] [PMID]

[22] Willers SM, Devereux G, Craig LC, McNeill G, Wijga AH, Abou El-Magd W, et al. Maternal food consumption during pregnancy and asthma, respiratory and atopic symptoms in 5-year-old children. Thorax. 2007; 62(9):773-9. [DOI:10.1136/thx.2006.074187] [PMID] [PMCID]

[23] Martindale S, McNeill G, Devereux G, Campbell D, Russell G, Seaton A. Antioxidant intake in pregnancy in relation to wheeze and eczema in the first two years of life. American Journal of Respiratory and Critical Care Medicine. 2005; 171(2):121-8. [DOI:10.1164/rccm.200402-220OC] [PMID]

[24] Litonjua AA, Rifas-Shiman SL, Ly NP, Tantisira KG, Rich-Edwards JW, Camargo CA. Maternal antioxidant intake in pregnancy and wheezing illnesses in children at $2 \mathrm{y}$ of age. Am. J. Clin. Nutr. 2006; 84:903-11. [DOI:10.1093/ajcn/84.4.903] [PMID] [PMCID]

[25] Miyake Y, Sasaki S, Tanaka K, Hirota Y. Consumption of vegetables, fruit, and antioxidants during pregnancy and wheeze and eczema in infants. Allergy. 2010; 65:758-65. [DOI:10.1111/ j.1398-9995.2009.02267.x] [PMID]

[26] West CE, Dunstan J, McCarthy S, Metcalfe J, D’Vaz N, Meldrum $\mathrm{S}$, et al. Associations between maternal antioxidant intakes in pregnancy and infant allergic outcomes. Nutrients. 2012; 4:174758. [DOI:10.3390/nu4111747] [PMID] [PMCID]

[27] Nwaru BI, Erkkola M, Ahonen S, Erkkola M, Ahonen S, Pekkanen J, et al. Intake of antioxidants during pregnancy and the risk of allergies and asthma in the offspring. Eur J Clin Nutr. 2011; 65:937-43. [DOI:10.1038/ejcn.2011.67] [PMID]

[28] Greenough A, Shaheen SO, Shennan A, Seed PT, Poston L. Respiratory outcomes in early childhood following antenatal vitamin C and E supplementation. Thorax. 2010; 65:998-1003. [DOI:10.1136/thx.2010.139915] [PMID] 
This Page Intentionally Left Blank 